\title{
Eccema herpético por virus herpes simplex tipo 2. Revisión de la literatura a propósito de un caso
}

\author{
Francisca Schroeder H., Andrea Elgueta N. y M. José Martínez G.
}

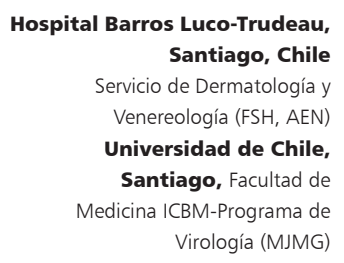

Recibido: 28 de marzo de 2008 Aceptado: 20 de enero de 2009

Correspondencia a: Francisca Schroder Hanke lulateno@hotmail.com

\section{Eczema herpeticum caused by herpes simplex virus type 2 . Review of the literature about one case}

Eczema herpeticum is an extensive vesicular eruption caused by cutaneous dissemination of herpes simplex virus in patients who have underlying skin conditions or epidermal barrier disruption. Herpes simplex virus type 1 (HSV 1) is the most common etiology. This is the first report in Chile of a case of eczema herpeticum caused by HSV 2 in a patient with Darier's disease, We review the literature and emphasize the use of sensitive and specific assays as real time polimerase chain reaction, that allow to initiate timely the correct treatment.

Key words: Eczema herpeticum, Kaposi varicelliform eruption, herpes simplex virus type 2.

Palabras clave: Eccema herpético, erupción variceliforme de Kaposi, virus herpes simplex tipo 2.

\section{Introducción}

$\mathrm{E}$ 1 eccema herpético es la diseminación cutánea del virus herpes simplex, en pacientes portadores de enfermedades crónicas de la piel, principalmente dermatitis atópica. También ocurre en pacientes portadores de otras patologías cutáneas crónicas (enfermedad de Darier, pitiriasis rubra pilaris, psoriasis y otras menos frecuentes), o que presentan daño de la barrera epidérmica.

La mayoría de los casos descritos en la literatura son causados por VHS $1^{2-6}$ y sólo existen algunos casos publicados de eccema herpético por VHS $2^{7,8}$. Presentamos el primer reporte de eccema herpético por VHS 2 en nuestro país.

\section{Caso Clínico}

Hombre de 45 años, previamente sano, derivado desde el Servicio de Urgencia al Servicio de Dermatología del Hospital Barros Luco Trudeau, por un cuadro de dos semanas de evolución, caracterizado por la aparición aguda y progresiva de lesiones cutáneas en el tronco. En la historia clínica sólo destacaba el antecedente de una erupción recurrente del tronco desde los 18 años de edad, caracterizada por pápulas eritematosas asintomáticas en la región preesternal y brazos. Sin antecedentes de infecciones herpéticas de la piel o genitales, ni enfermedades cutáneas familiares. Al examen físico se encontraba en regular estado general, afebril y presentaba múltiples pápulas y pústulas umbilicadas en el tronco, confluentes, con algunas lesiones en etapa de costra (Figuras 1 y 2). Sin lesiones en la cara, genitales ni mucosas. En las manos destacaba la presencia de pápulas aplanadas color piel en el dorso, pits palmares y alternancia de líneas rojas y blancas en las uñas, hallazgos sugerentes de enfermedad de Darier (Figura 3). Se hospitalizó con el diagnóstico presuntivo de eccema herpético y enfermedad de Darier. Se realizaron exámenes generales, cultivo corriente y reacción de polimerasa en cadena (RPC) para virus herpes simplex de las pústulas, y una biopsia de las lesiones de piel sugerentes de enfermedad de Darier. Empíricamente se indicó tratamiento con aciclovir oral $400 \mathrm{mg} 5$ veces al día y cloxacilina ev 1 gr cada 6 hrs, el que se mantuvo durante 10 días. Entre los exámenes generales se encontró un hemograma normal, VHS $29 \mathrm{~mm} / \mathrm{h}$, PCR $123 \mathrm{mg} / \mathrm{L}$, GGT 108 U/L. Los resultados del VDRL y las serologías para VIH y VHB fueron negativos. El cultivo de piel fue positivo para Staphylococcus aureus resistente sólo a clindamicina y eritromicina, y la RPC en tiempo real, realizada en el Laboratorio de Virología del Instituto de Ciencias Biomédicas de la Facultad de Medicina de la Universidad de Chile, fue positiva para VHS 2. Los hallazgos histopatológicos de la biopsia de piel fueron compatibles con enfermedad de Darier. El paciente respondió rápidamente al tratamiento, siendo dado de alta a los 10 días. 

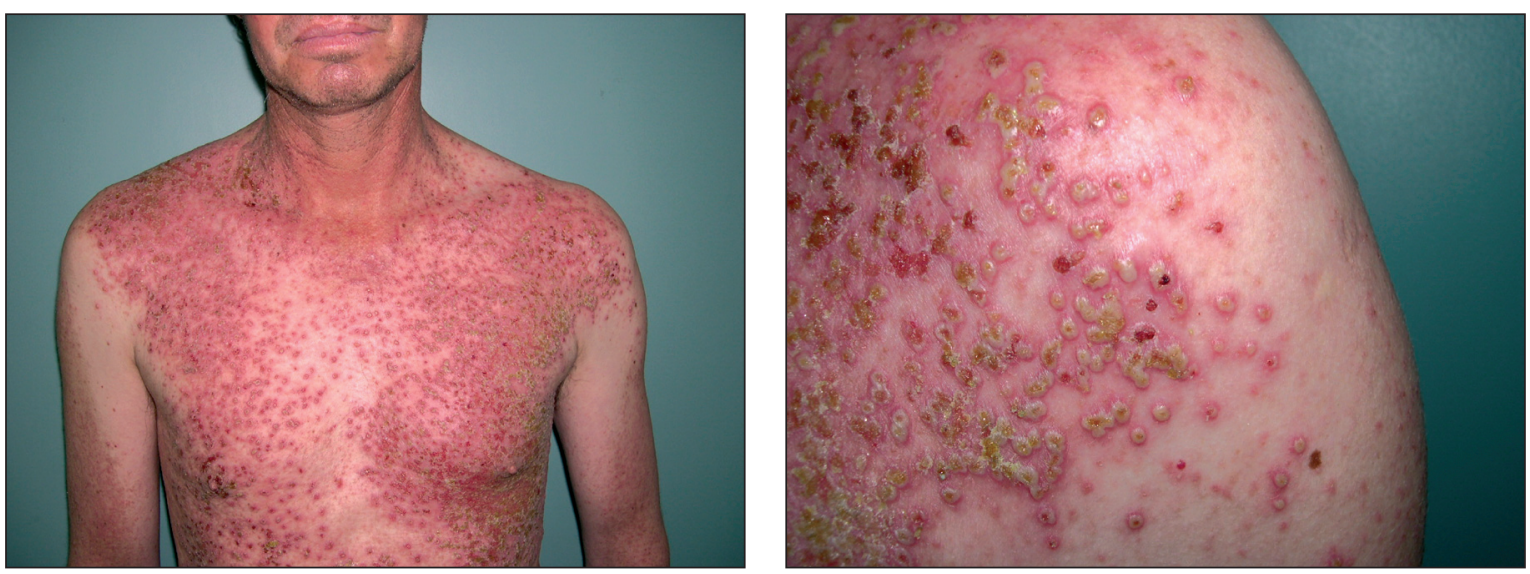

Figura 1. Pápulas y pústulas umbilicadas confluentes en el tronco.

\section{Discusión}

Los pacientes con enfermedades crónicas de la piel, especialmente los portadores de dermatitis atópica, tienen mayor riesgo de desarrollar una diseminación cutánea de ciertos virus como: virus herpes simplex, virus Coxsackie A16 y el virus vaccinia ${ }^{1,9,10}$. Este cuadro clínico se conoce como erupción variceliforme de Kaposi.

La causa más frecuente de la erupción variceliforme de Kaposi, es la diseminación del virus herpes simplex en pacientes atópicos, lo que se ha denominado más específicamente eccema herpético. Sin embargo, el término eccema herpético también se utiliza para la diseminación cutánea del virus herpes simplex en pacientes portadores de otras patologías cutáneas crónicas (enfermedad de Darier, linfoma cutáneo de células $\mathrm{T}$, pitiriasis rubra pilaris, pénfigo familiar benigno, eritrodermia ictiosiforme congénita, dermatitis seborreica, síndrome de WiscottAldrich, psoriasis, lupus eritematoso) o que presentan daño de la barrera epidérmica (dermatitis de contacto, quemaduras, injertos, dermoabrasiones). De forma similar, la diseminación del virus vaccinia en pacientes atópicos (o portadores de otras dermatosis) se conoce como eccema vaccinatum ${ }^{1}$. Actualmente, la vacunación contra la viruela (enfermedad erradicada del mundo al final de la década de 1970) está indicada sólo en situaciones de emergencia (brote de viruela) y en personal de laboratorio o trabajadores de la salud que se encuentren en riesgo de adquirir el virus vaccinia o virus afines. Debido a que el eccema vaccinatum es una complicación seria de esta vacuna, el CDC de Atlanta considera que el antecedente personal de dermatitis atópica es una contraindicación para la vacunación ${ }^{1,11,12}$.

Se han propuesto diferentes mecanismos inmunológicos para explicar el eccema herpético en pacientes atópicos: una alteración de la inmunidad contra el virus herpes simplex mediada por células $\mathrm{T}$, un defecto en los anticuerpos específicos contra el virus, una disminución de las células NK y los receptores de IL-2, una inhibición de la respuesta Th-1 por aumento de IL-4, disminución de las catelicidinas (una familia de péptidos antimicrobianos que forman parte de la inmunidad innata) o una disminución de las células dendríticas plasmocitoides productoras de interferón tipo $\mathrm{I}^{1,13}$. Otra posibilidad es que simplemente la diseminación viral esté favorecida por la disrupción de la barrera cutánea que existe, tanto en la dermatitis atópica como en las otras patologías de la piel asociadas a eccema herpético ${ }^{1}$.

Un estudio restropectivo de 100 casos de eccema herpético demostró como únicos factores de riesgo, una edad de inicio temprana de la dermatitis atópica y niveles altos de IgE total en atópicos, y descartó el uso de corticosteroides tópicos como factor predisponente ${ }^{14}$. Algunos

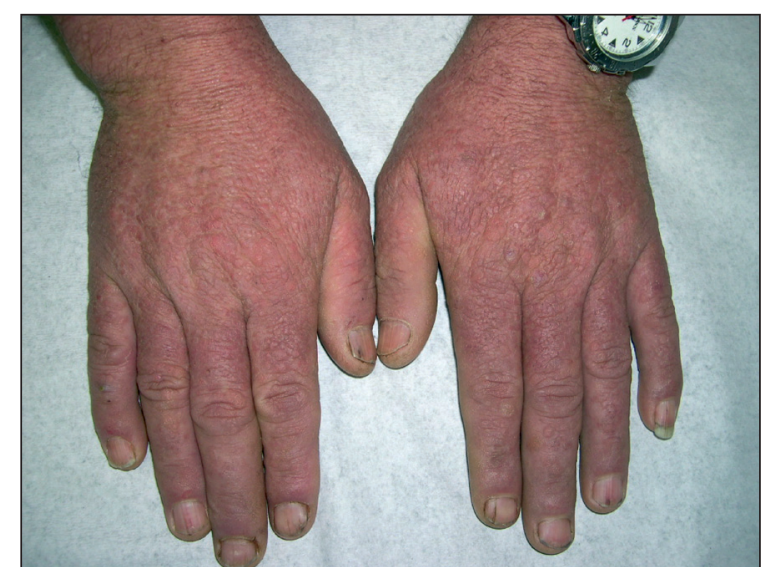

Figura 2. Detalle de las lesiones. Pápulas y pústulas umbilicadas, confluentes, algunas costrosas.
Figura 3. Pápulas aplanadas en el dorso de las manos. 
reportes de casos y estudios prospectivos han encontrado una asociación entre el uso tópico de inhibidores de la calcineurina en pacientes atópicos y el desarrollo de eccema herpético ${ }^{15-19}$.

El eccema herpético puede ser consecuencia de una primoinfección o de una recurrencia del virus herpes simplex. La mayoría de los casos reportados han sido causados por VHS $1^{2-6}$ y sólo encontramos dos casos publicados por VHS $2^{7,8}$. Coincidentemente los dos casos por VHS 2 se presentaron en pacientes con enfermedad de Darier, un raro trastorno de la queratinización, de herencia autonómica dominante, con penetrancia variable, caracterizado por pápulas hiperqueratósicas en áreas seborreicas, que se manifiesta en la pubertad, con exacerbaciones y remisiones a lo largo de la vida ${ }^{3}$.

La forma primaria de eccema herpético (o primer episodio) se caracteriza por una erupción monomorfa constituida por vesículas que progresan a vesículopústulas umbilicadas y que pueden coalescer formando placas costrosas con un grado de hemorragia variable, características de la enfermedad. Las lesiones aparecen inicialmente sobre la piel dañada por la patología cutánea subyacente y se diseminan progresivamente en 7 a 10 días, acompañándose de fiebre, calofríos y adenopatías. También existen las formas localizadas, sin diseminación extensa. El promedio de duración de la enfermedad es de 16 días (rango de 2 a 6 semanas) $)^{1,13}$.

Entre 13 y $16 \%$ de los pacientes pueden desarrollar episodios recurrentes de eccema herpético ${ }^{14}$. En estos casos el cuadro clínico es más limitado, con menor compromiso del estado general ${ }^{1,13}$.

La complicación más frecuente de estos pacientes es la sobre-infección bacteriana de las lesiones, siendo $S$. aureus el agente aislado con mayor frecuencia ${ }^{20}$. Otras complicaciones más graves son la viremia secundaria con compromiso de otros órganos, sepsis bacteriana o la infección ocular por virus herpes simplex. Pese a la elevada frecuencia de lesiones faciales, la queratitis herpética es rara, incluso en pacientes en los que se ha aislado el virus de la mucosa conjuntival ${ }^{1,13}$.

El diagnóstico clínico de eccema herpético debe sospecharse ante la presencia de lesiones características en un paciente con una alteración de la barrera cutánea de base, especialmente en dermatitis atópica. Los principales diagnósticos diferenciales son la infección por VVZ, impétigo y dermatitis de contacto. La presencia y el tipo de virus herpes simplex involucrado pueden confirmarse mediante aislamiento viral, inmunofluorescencia o RPC de una muestra obtenida con tórula del piso de las vesícu- las. Si esto no es posible, la presencia de células gigantes multinucleadas en el test de Tzanck puede orientar al diagnóstico de infección herpética; su sensibilidad puede alcanzar al 70\% dependiendo del estado de la lesión, es un método rápido, barato y que permite un inicio precoz de tratamiento antiviral. La biopsia de piel muestra los cambios histológicos característicos de la infección herpética (epidermis con edema intra e intercelular, cuerpos de inclusión eosinofílicos intranucleares y células gigantes multinucleadas). Si se sospecha una sobre-infección bacteriana de las lesiones debe realizarse un cultivo corriente $^{1,13}$

El pilar del tratamiento del eccema herpético es los análogos de nucleósidos activos contra el virus herpes simplex, como aciclovir o valaciclovir, con lo que ha disminuido la letalidad de esta patología de 50\% a menos del $10 \%{ }^{13}$. Existe un ensayo clínico controlado, multicéntrico, doble ciego y randomizado, que comparó $200 \mathrm{mg} 5$ veces al día de aciclovir oral por 5 días versus placebo, en 60 pacientes inmunocompetentes. Este estudio demostró que la terapia con aciclovir en estas dosis acelera la recuperación clínica de los pacientes y disminuye la duración de las úlceras, encontrándose todos los pacientes sin lesiones al décimo día de iniciado el tratamiento. No se encontró una diferencia significativa en la duración de la excreción viral entre los dos grupos ${ }^{8}$. Sin embargo, dado que el eccema herpético es una patología grave se recomienda usar valaciclovir ( 1 gr cada 8 horas durante 7 a 10 días, según la evolución del paciente), debido a su mayor biodisponibilidad ${ }^{1}$. Debe tenerse en cuenta también que, de acuerdo a la gravedad del paciente, podría usarse aciclovir ev.

\section{Resumen}

El eccema herpético es una erupción vesicular extensa causada por la diseminación cutánea del virus herpes simplex, en pacientes con trastornos cutáneos previos o daño de la barrera epidérmica. La etiología más frecuente es virus herpes simplex tipo 1 (VHS 1), aunque se han reportado casos de virus herpes simplex tipo 2 (VHS 2). Presentamos el primer reporte en Chile de eccema herpético por VHS 2 en un paciente con enfermedad de Darier. Realizamos una revisión de la literatura médica y destacamos la importancia del uso de técnicas sensibles y específicas como la reacción de polimerasa en cadena (RPC) en tiempo real, que posibilitan el inicio precoz de la terapéutica correcta. 


\section{Referencias}

1.- Kramer S, Thomas C, Tyler W, Elston D. Kaposi's varicelliform eruption: A case report and review of the literature. Cutis 2004; 73: 115-22.

2.- Pantazi V, Potouridou I, Katsarou A, Papadogiorgaki H, Katsambas A. Darier's disease complicated by Kaposi's varicelliform eruption due to herpes simplex virus. J Eur Acad Dermatol Venereol 2000; 14: 209-11.

3.- Roustan G, Portero F, Martín P. Erupción vesiculosa aguda en tronco. Enferm Infecc Microbiol Clin 2002; 20: 533-4.

4.- Saraswat A, Ratho K, Kumar B. Two unusual cases of Kaposi's varicelliform eruption. Acta Derm Venereol 2002; 82: 138-9.

5.- Kosann M K, Fogelman J P, Stern R L. Kaposi's varicelliform eruption in a patient with Grover's disease. J Am Acad Dermatol 2003; 49: 914-5.

6.- Umene K, Yoshida M, Sakaoka H. Comparison of the association with eczema herpeticum in the two predominant genotypes of herpes simplex virus type 1. J Med Virol 1996; 49: 329-32.

7.- Hazen P G, Eppes R B. Eczema herpeticum caused by herpesvirus type 2 . A case in a patient with Darier disease. Arch Dermatol 1977; 113 : 1085-6.
8.- Niimura M, Nishikawa T. Treatment of eczema herpeticum with oral acyclovir. Am J Med 1988; 85 (2A): 49-52.

9.- Monckton-Copeman P W, Wallace H J. Eczema vaccinatum. Br Med J 1964; 2: 906-8.

10.- Salo O P, Valle M J. Eczema vaccinatum in a family with Darier's disease. Br J Dermatol 1973; 89: 417-22.

11.- Engler R J, Kenner J, Leung D Y. Smallpox vaccination: Risk considerations for patients with atopic dermatitis. J Allergy Clin Immunol 2002; 110: 357-65.

12.- Cono J, Casey C G, Bell D M; Centers for Disease Control and Prevention. Smallpox vaccination and adverse reactions. Guidance for clinicians. MMWR Recomm Rep 2003; 52 (RR-4): 1-28.

13.- McKenna J K. Kaposi varicelliform eruption. www.emedicine.com/derm/topic 204.htm (accedido 17 de septiembre 2008).

14.- Wollenberg A, Zoch C, Wetzel S, Plewig G, Przybilla B. Predisposing factors and clinical features of eczema herpeticum: a retrospective analysis of 100 cases. J Am Acad Dermatol 2003; 49: 198-205.

15.- Lübbe J, Pournaras C C, Saurat J H. Eczema herpeticum during treatment of atopic dermatitis with $0.1 \%$ tacrolimus ointment. Dermatology
2000; 201: 249-51

16.- Miyake-Kashima M, Fukagawa K, Tanaka M, Takano Y, Dogru M, Asano-Kato N, et al. Kaposi varicelliform eruption associated with $0.1 \%$ tacrolimus ointment treatment in atopic blepharitis. Cornea 2004; 23: 190-3.

17.- Papp K A, Werfel T, Fölster-Holst R, Ortonne J P, Potter P C, de Prost Y, et al. Long-term control of atopic dermatitis with pimecrolimus cream $1 \%$ in infants and young children: a two-year study. J Am Acad Dermatol 2005; 52: 240-6.

18.- Paul C, Cork M, Rossi A B, Papp K A, Barbier N, de Prost Y. Safety and tolerability of $1 \%$ pimecrolimus cream among infants: experience with 1.133 patients treated for up to 2 years. Pediatrics 2006; 117: e118-28. Epub 2005 Dec 15.

19.- Osawa K, Etoh T, Ariyoshi N, Ishii I, Ohtani M, Kariya S, et al. Relationship between Kaposi's varicelliform eruption in Japanese patients with atopic dermatitis treated with tacrolimus ointment and genetic polymorphisms in the IL-18 gene promoter region. J Dermatol 2007; 34: 531-6.

20.- Brook I, Frazier E H, Yeager J K. Microbiology of infected eczema herpeticum. J Am Acad Dermatol 1998; 38: 627-9. 